Katarzyna Walęcka-Matyja, Ph.D.

Unit of Social Psychology and Family Research

Institute of Psychology, Faculty of Educational Sciences

University of Lodz, 91-433 Łódź, Smugowa 10/12

Poland

Dominika Kurpiel, Ph.D.

Unit of Psychology, Institute of Pedagogy

Faculty of Education and Philosophy

Pomeranian Academy of Słupsk

\title{
PSYCHOLOGICAL ANALYSIS OF STRESS COPING STYLES AND SOCIAL SUPPORT IN MEN WITH PHYSICAL DISABILITY
}

\section{Introduction}

Difficult situations, when the ways of coping with the demands of circumstances are insufficient, always cause a state of tension and a loss of internal balance. That can mean stress as a temporary, chronic, permanent, progressing or periodical condition. However, the quality of coping with a difficult situation depends not only on a type of experienced stress but mainly on taking remedial measures. The way the person will behave ${ }^{11}$ decides on how they will be able to adapt to the new conditions or shows that they have no such ability.

The style of coping with difficulties used by an individual depends on many determinant factors, both situational and personality-related (including, among other factors, the level of self-esteem, optimism, apprehensiveness, achievements). The choice of a given strategy is also affected by other variables, such as: age, sex, education or current psycho-physiological condition. Therefore, different people behave in very different ways in the same situation as well as the same person behaves

\footnotetext{
${ }^{1}$ The reference books name different ways of coping with stress although they have not been ordered into one classification so far (Terelak, 1995; Heszen -Niejodek, 2000; Juczyński, 2000).
} 
in different ways in different situations. A very important notion in the research of coping with stress is the concept of flexibility. It is understood as a style feature conditioning the strategy change based on the demands of circumstances. Thereby, it decides about the effectiveness of the coping behaviour (Heszen - Niejodek, 2000). However, when a person, being under the influence of tension, loses their adaptation abilities, they fall into helplessness, withdraw from life and suffer.

The situation of losing motor skills undoubtedly contributes to the experience of suffering. For sure, disability violates the most important human values, which include health, physical agility, ability to achieve their social roles, it is also an obstacle to achieve their objectives (Stelter, 2010).

Physical disability may result from amputations or lack of limbs, inborn deformations, dysfunctions as a result of spinal cord injuries, paralyses (Szczepankowska, Mikulski, 1999).

Due to the fact that the problem how people with physical disability resulting from spinal cord injuries function has hardly ever been presented in the reference literature, this study provides a psychological analysis of the behaviour in a difficult situation of men with tetraplegia ${ }^{22}$.

Tetraplegia can be qualified to the category of personal stressors (non-normative). In the course of this disease, there are periods which are undoubtedly connected with stress, both for an individual and for their closest environment, the family.

Difficult situations caused by tetraplegia concern all the human functioning spheres: biological, psychological, mental and social.

In the biological sphere, the persons who survived a spinal cord injury suffer from complications, such as chronic pain, dysfunctions of bladder and intestines, and they also have breathing and circulatory problems. Moreover, their sexual and parental functions are affected. It needs to be remembered that a spinal cord injury has a bigger influence on sexual functions in men than in women. In fact, the majority of women after a spinal cord injury remains fertile and can bear children. Also, it appears that even a serious spinal cord injury does not deprive women of the possibility of achieving sexual satisfaction. Whereas, in men, depending on how high the spinal cord has been injured, some serious problems with taking up sexual activity may occur.

In the psychological sphere, a patient with tetraplegia can struggle with the feelings of despondency, fatigue or depression caused by monotony and no visible effects of the treatment. Some of the ill people experience fear, despair and even show suicidal tendencies. They can also become increasingly egocentric and have the strong needs for human contact and care. The physically disabled miss

\footnotetext{
${ }^{2}$ Tetraplegia is the paralysis of four limbs. Its effects seriously limit a man's agility and the basic feature of the lesions is their irreversibility. The pathogenesis usually has a nature of a sudden incident in which a person's cervical spine has been injured (Brzezińska, 2007).
} 
performing usual activities on their own, like, for example, walking up the stairs or playing football. A lot of them start to feel anxiety about the future, their own fate and the fate of their relatives. The disabled have fewer and fewer interests, they become apathetic, indifferent to the surrounding world and the people.

In the mental sphere, the chronically ill show a range of different reactions. They are placed on the continuum from the tendency of escape from faith, rebellion, losing the sense of life and refusing to understand the sense of suffering, doubt in the power of love up to devotion to God and showing altruistic attitudes.

In the sphere of social relations, difficult situations resulting from the disease are mainly connected with the lack of acceptance of the situation the ill person is in. That manifests itself in the extreme criticism of other people and setting excessive requirements for the environment. The patient has a groundless feeling of social harm and can show a priori reluctance to any form of help received from communities (Heszen- Niejodek, 2000).

Rehabilitation and adaptation to the new circumstances depend, to a great extent, on how the ill person copes with the above-described difficulties on a daily basis.

Considering the exceptionality of the psychological situation of men with tetraplegia, we should take into account their physical abilities resulting from their limitations as well as their personality resources, social support and the ability of coping with stress (Brzezińska, 2007).

\section{The Research Problem and Objectives}

The analysis concerned the psychological styles of coping with a chronic disease, an example of which undoubtedly is tetraplegia. The objective of the research was to compare the stress coping styles used by the groups of men with tetraplegia and healthy ones. The research also included comparison of behaviours connected with using social support by the men from both groups.

The role of social support in the process of struggling with a chronic disease is invaluable as it goes between the action of the stress generating factors (stressors) and feeling their consequences (Chojnacka-Szawłowska, 2000).

The results presented in the reference books indicate that the people surrounded with care by their relatives are healthier and better cope with difficult situations than the lonely ones, who are more often subject to illness and higher mortality rate (Knoll, Schwarzer, 2004; Steuden, Okła, 2007).

S. Sarason (1987) proposes a wide interpretation of social support, describing it as help available to a given person in difficult situations. Social support understood like that can be discussed in many ways, considering different criteria: a source of social support (family, friends, institutions) - in structural terms; types of social support (emotional, information, instrumental, evaluating, mental) - in 
functional terms; the perceived support, the received support, the need for support, the desirable support, the sought support, support mobilization (Sęk, 2001).

Coping with physical disability meant as a stressful situation requires seeking and using social support. As research shows, the way of experiencing a chronic disease affects the need for different degree and type of support from the social surroundings (Kirenko, 2002).

It has been stressed that social support appropriately adjusted to the needs of an ill person makes it easier for them to cope with a difficult situation. Appropriateness of the provided help is connected, among other things, with knowing the person's needs as regards the amount, type and source of support as well as with knowing the current stage of struggling with the chronic disease (Steuden, Okła, 2007). Support which is not consistent with the needs of a disabled person may lead to the formation of non-adaptational features or behaviours in the supported person (Sęk, 2001).

Social support is one of the many human resources used in order to overcome difficulties. Another one strongly related to coping with stress is the coping style ${ }^{33}$ and using the given remedial strategies. In the light of the above-mentioned, it is stated that coping with a difficult situation is an individual process, typical of every human being (Heszen-Niejodek, 2007).

The present study uses the stress coping style classification represented by the concept of N. S. Endler and J. D. Parker. The authors distinguish three basic styles of coping with stress, namely: task-oriented, emotion-oriented and avoidance-oriented.

The task-oriented style is preferred by the persons who, in a stressful situation, make a mental effort aimed at solving the problem through cognitive transformations.

The emotion-oriented style is characteristic of the persons with tendency to focus on themselves, on their own internal emotional experiences, such as anger, tension or guilt, which in stressful situations may lead to wishful thinking and fantasizing in order to relieve the experienced tension. However, the range of the above-mentioned stress coping styles can in many cases lead to the growth of tension, depression and rumination and experiencing negative emotions.

The avoidance-oriented style is typical of the persons who have escapist tendencies manifesting themselves in the avoidance of thinking about, experiencing negative emotions connected with a difficult situation. This process may take one of the two forms.

a) engaging in displacement activities, i.e. stuffing oneself, excessive drowsiness, pleasure activities,

\footnotetext{
${ }^{3}$ The notion of a coping style refers to a relatively stable, typical of an individual, tendency of coping with difficult situations (Heszen-Niejodek, 2007).
} 
b) looking for company, which is also a form of escape from the problem (Endler, Parker, 1990; Wrześniewski, 1996).

As it has been shown, the most constructive way of coping with stress resulting from disability is the style making the person focus on a task and involve in action (Parchomiuk, Byra, 2007).

Analyzing the reference books, we can get an impression that some authors refer to a difference which is often difficult to grasp between the following notions: chronic disease and disability (Kulesza, 2000; Krasuska-Betiuk, 2010).

The chronic disease is most often identified with the effect of a chronic factor causing a prolonged illness characterized by mild symptoms lasting for months or even years (Góralczyk, 1996). However, it can also result from a sudden unexpected incident, for example, a traffic accident.

The chronic disease qualities usually include: long period of the disease process and treatment, uncertain prognosis, necessity of frequent stays in hospital and systematic checkups. Moreover, a chronically ill patient is affected by physical and mental suffering related both to the illness and to the treatment. And, what a chronically ill person can expect in the nearer or further future is the state of disability understood as decreasing physical agility, change of appearance, addiction to medical drugs, procedures and frequently troublesome symptoms, such as excessive sweating or incontinence. The state of disability significantly limits the functioning of a man, in realizing both their family and professional roles (Góralczyk, 1996; Juczyński, 2000).

The interpretation of the notion of a disabled person, occurring in the reference books, is usually formulated in two categories, i.e. biological and social.

The biological (medical) interpretation focuses on the injury of organs and their activity causing deterioration of their functioning and the functioning of the whole organism, considering the fact that all the activities are reciprocally conditioned and coordinated.

The social interpretation, on the other hand, points at the consequences of this injury and the reduction of efficiency in various spheres of life and at the person's relationships with the environment where they live and work (Golinowska, 2004). Therefore, in this study, the terms of a chronic disease, disability shall be used interchangeably.

\section{The Research Questions and Hypotheses}

Bearing in mind the research reports included in the reference books, the following research questions and hypotheses have been formulated:

1. Is there any differentiation with regard to the used stress coping styles in the examined groups of physically disabled and healthy men? 
2. Does the perceived level of social support differentiate the examined groups of men?

3. Are there any correlations and of what kind between the stress coping styles and the social support levels?

H1: Men with tetraplegia show a lower level of using the adaptational stress coping styles in difficult situations than able-bodied men.

$\mathrm{H} 2$ : The perceived level of social support is lower in the group of men with tetraplegia than in the group of healthy men.

H3: There are correlations between the stress coping styles and the perceived level of social support.

\section{The Research Methods}

The methods used in the research included: an individual questionnaire and standardized questionnaires: Coping Inventory for Stressful Situations (CISS) by N.S. Endler and D.A. Parker and Berlin Social Support Scales (BSSS) in the Polish version created by Ralf Schwarzer, A. Łuszczyńska, M. Kowalska and M. Mazurkiewicz (2006).

Individual Questionnaire was used in order to collect data of a demographic nature, i.e. sex, age, domicile, marital status, education, professional activity, economic situation of the examined.

Coping Inventory for Stressful Situations (CISS) by N.S. Endler and D.A. Parker in the adaptation of P. Szczepaniak et al. (2007) was used to establish the typical way of behaviour of the examined people in different stressful situations. The CISS questionnaire consists of 48 simple statements which are connected with different behaviours shown in difficult situations. A survey respondent is asked to take an attitude towards each statement by marking a number which reflects the frequency of the performed activity most accurately (from 1 to 5).

The scores are obtained separately for each scale, through summing the weights according to the key. The authors created three scales mentioned below, which determine the stress coping styles.

The first scale (16 items) refers to the stress coping style which is task-oriented. High scores in this scale show that the examined person has a tendency, in difficult situation, to make efforts aimed at solving the problem through cognitive transformation or an attempt of changing the situation.

The second scale (16 items) describes the stress coping style which is emotion-oriented. It is typical of the people showing, in stressful situations, a tendency to focus on themselves and their own emotional experiences. They also have a tendency of wishful thinking and fantasizing.

The last, third scale (16 items) identifies the stress coping style which is avoidance-oriented. The persons obtaining high scores in this scale are characterized 
by a tendency to avoid the cognitive and emotional experiences of the stressful situation. This style may take two forms: engaging in displacement activities (8 items), for example, stuffing oneself or sleep or looking for company (5 items).

The psychometric dimensions of the Polish version of the CISS questionnaire allow us to treat this tool as accurate and reliable, suitable to measure stress coping styles (Strelau, Jaworowska, Wrześniewski, Szczepaniak, 2007).

Berlin Social Support Scales (BSSS) by Ralf Schwarzer were used in order to determine the level of different types of social support, i.e. the available support, the need for support, seeking support, the received support and the protective support.

The available support shall be understood as the availability of help from other people, and the received support reduces the perceived threat in stressful situations. The perceived available support directly affects health and wellbeing without the contribution of the situational factors. The need for support is included in the definition of the need for using support in stressful situations. Seeking support combines both the frequency and the range of looking for help from other people. The last support model is the protective support understood as the protection of the closest people from bad information (Schulz, Schwarzer, 2003).

Berlin Social Support Scales are a psychometrically acceptable tool, which makes it possible to use it in researches ${ }^{44}$.

\section{The Sample Group Profile}

The research included 50 men coming from urban agglomerations: Łódź and Słupsk. 45 men (including 20 with diagnosed tetraplegia and 25 able-bodied ones) were qualified to the sample group. The criteria of selection were: the state of health or the moment of acquiring the disability, its scope in the context of the clinical and bio-social classification (the source of information included: the patient's individual medical card and the clinical and community interview with the patient and his family) and the completeness of filling the test forms.

In the group of able-bodied men, the average age was 27 whereas in the group of men with physical disability it was 32 . The examined men's disability is acquired. It is a result of a spinal cord injury within the cervical spine caused by traffic accidents and diving. In the reference books, this kind of disability is called acquired tetraplegia.

\footnotetext{
${ }^{4}$ The psychometric qualities of Berlin Social Support Scales are included in the article: Schwarzer, R., Łuszczyńska, A., Mazurkiewicz, M., Kowalska, M. (2006). Berlin Social Support Scales (BSSS). The results of the introductory studies on the scales adaptation and their psychometric qualities. "Psychological Studies" 44 (3), p. 17-27.
} 
In both sample groups, most men had secondary education $(65.4 \%$ of the men with acquired tetraplegia and $82.7 \%$ of the healthy men). While taking the variable of professional activity into account, it was noticed that in the group of disabled men, there were more economically inactive ones (inactive, looking for a job) whereas in the group of healthy men, there were more working persons. The demographic variable statistically differentiating the compared groups was the marital status (Chi-square $=6.122 ; \mathrm{df}=2 ; \mathrm{p}<.047$ ). In the group of healthy people, there were more married men $(21.2 \%)$ than in the group of men with tetraplegia $(5.8 \%)$. In the group of men with tetraplegia, there were more single men $(92.3 \%)$ whereas in the group of healthy men, unmarried men accounted for $78.8 \%$ of the examined persons. Describing the group of men with tetraplegia, it is worth mentioning that in most cases, the time that had passed since the accident was 5 years or longer. In most men, the injury was caused by a traffic accident.

\section{The Research Results}

The collected empirical material was analyzed from the statistical perspective. To do so, a computer program, SPSS PC+ was used. The statistical analysis of the results included the issues corresponding with the individual research questions. To select a test to be used to compare the average scores obtained by the sample groups of men with physical disability and able-bodied ones in the scope of the specified psychological variables (stress coping style and social support), the Levene's test was applied. The received results allowed us to use a Student's t-test. To measure the correlations between the stress coping styles and the perceived support levels, the correlation coefficient (Pearson's r) was used.

\section{The Stress Coping Styles Profile in the Group of Men with Physical Disability and Healthy Ones}

To verify the hypothesis stating that the men with tetraplegia show a lower level of using the adaptational stress coping styles than the able-bodied ones, an analysis of difference significance for independent samples was carried out. It appeared that there are significant differences with regard to the styles of coping with difficult situations between the compared sample groups of men (tab. 1 and fig. 1). 
Table 1. Differentiation of stress coping styles in the sample groups of men

\begin{tabular}{|l|c|c|c|c|}
\hline \multirow{2}{*}{$\begin{array}{l}\text { Stress } \\
\text { coping } \\
\text { groups } \\
\text { styles }\end{array}$} & \multicolumn{2}{|c|}{ Average scores in sample groups } & & \\
\cline { 2 - 3 } & $\begin{array}{c}\text { Men with tetraplegia } \\
\mathrm{N}=20\end{array}$ & $\begin{array}{c}\text { Healthy men } \\
\mathrm{N}=25\end{array}$ & t & P \\
\hline Task & $\bar{x} \delta$ & 58.284 .68 & .827 & .413 \\
\hline Emotions & 57.055 .27 & 34.369 .21 & -3.441 & .001 \\
\hline Avoidance & 43.558 .48 & 42.9610 .32 & -3.514 & .001 \\
\hline Displacement activities & 53.058 .53 & 18.925 .08 & -2.180 & .035 \\
\hline Social contacts & 22.355 .44 & 17.043 .93 & -3.150 & .003 \\
\hline
\end{tabular}

Signs: $\bar{X}$ - average; $\delta$ - standard deviation; t- Student's t-test; $\mathrm{p}$ - significance level

Source: Own work

In stressful situations, the men with tetraplegia used the emotion-oriented style and the avoidance-style more often than the healthy men. You can also notice statistically significant differences with regard to taking actions aimed at avoiding confrontation with a difficult situation by the examined men from both groups. The men with tetraplegia significantly more often engaged in social contacts and took up displacement activities. Only with regard to the task-oriented style, there were no statistically significant differences between the examined groups of men.

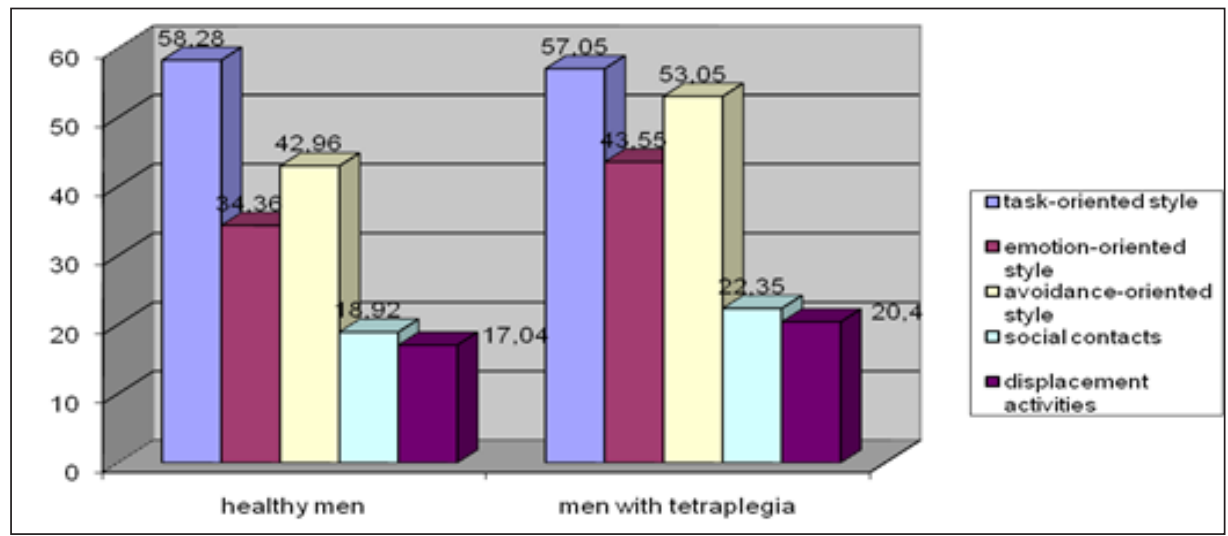

Figure 1. Comparison of average scores in respect of stress coping styles used by the examined men.

Source: Own work 
Thanks to the analysis presented above, it was possible to verify positively the first hypothesis assuming that there is a differentiation in respect of the stress coping styles applied by the groups of men with tetraplegia and healthy ones.

\section{Social Support in the Compared Groups of Men with Physical Disability and Healthy Ones}

Considering the second research question concerning differences in respect of the perceived social support in the sample groups of men with physical disability and able-bodied ones, we used a t-test (tab. 2 and fig. 2).

Table 2. Differentiation of social support perception in the sample groups of men

\begin{tabular}{|c|c|c|c|c|}
\hline \multirow[b]{2}{*}{$\begin{array}{l}\text { Social } \\
\text { support }\end{array}$} & \multicolumn{2}{|c|}{ Average scores in sample groups } & \multirow[b]{2}{*}{$\mathbf{t}$} & \multirow[b]{2}{*}{$\mathbf{P}$} \\
\hline & $\begin{array}{c}\text { Men with tetraplegia } \\
\qquad \begin{array}{c}\mathrm{N}=20 \\
\bar{x} \delta\end{array}\end{array}$ & $\begin{array}{l}\text { Healthy men } \\
\qquad \begin{array}{c}\mathrm{N}=25 \\
\bar{x} \delta\end{array}\end{array}$ & & \\
\hline Perceived available support & $25,704,29$ & $27,923,66$ & 2,313 & ,026 \\
\hline Need for support & $13,002,07$ & $9,762,33$ & $-4,858$ & ,000 \\
\hline Seeking support & $16,802,28$ & $11,002,55$ & $-7,936$ & ,000 \\
\hline
\end{tabular}

Signs: $\bar{x}$-average; $\delta$ - standard deviation; t- Student's t-test; $\mathrm{p}$ - significance level

Source: Own work

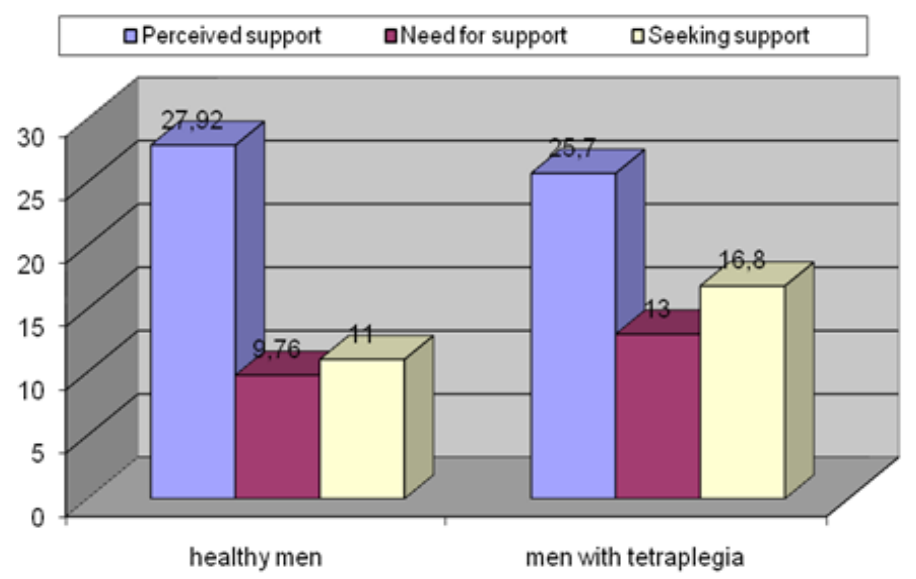

Figure 2. Comparison of average scores in respect of actions aimed at using social support taken by the examined men 
The data included in table 2 show that there are statistically significant differences in respect of perceiving support in the compared groups of men. The men with physical disability took actions aimed at seeking support more often than the able-bodied men, and they also showed the bigger need for support. Moreover, the perception of available support appeared to be a differentiating factor for the compared groups of men. The healthy men more often perceived support as available than the men with tetraplegia.

As it results from the presented analyses, the second hypothesis has been positively verified as all the examined dimensions of social support, i.e. its perceived availability, need for support and seeking support, differentiate the sample groups of men.

\section{Correlations Between Stress Coping Styles and Social Support Dimensions in the Sample Groups of Men}

Looking for the answer to the last research question concerning correlations between stress coping styles and social support dimensions, we used the correlation coefficient (Pearson's r). The results in this respect are included in table 3.

Table 3. Correlations between stress coping styles and social support dimensions

\begin{tabular}{|l|c|c|c|c|c|}
\hline $\begin{array}{r}\text { Stress } \\
\text { coping } \\
\text { styles }\end{array}$ & $\begin{array}{c}\text { Task-ori- } \\
\text { ented style }\end{array}$ & $\begin{array}{c}\text { Emotion- } \\
\text { oriented } \\
\text { style } \\
\text { Support }\end{array}$ & $\begin{array}{c}\text { Avoidance- } \\
\text { oriented } \\
\text { style }\end{array}$ & $\begin{array}{c}\text { Avoidance- } \\
\text { oriented style: } \\
\text { displacement } \\
\text { activities }\end{array}$ & $\begin{array}{c}\text { Avoidance- } \\
\text { oriented style: } \\
\text { social contacts }\end{array}$ \\
\hline Perceived support & 0.23 & -0.12 & 0.26 & 0.21 & 0.29 \\
\hline Need for support & -0.16 & 0.11 & $0.53^{* *}$ & $0.44^{* *}$ & $0.49^{* *}$ \\
\hline Seeking support & -0.18 & $0.33^{*}$ & $0.54^{* *}$ & $0.41^{* *}$ & $0.47^{* *}$ \\
\hline
\end{tabular}

$* \mathrm{p}<0.05 ; * * \mathrm{p}<0.01$

Source: Own work

As it results from the data included in table 3, the occurring correlations are exclusively positive.

The most important correlations occur between the avoidance-oriented style and its variations and the two support dimensions, i.e. the need for support and seeking support. It appears that the more often the examined men used the avoidance-oriented style, the more often they showed the need for support and took actions to seek it. 
The dimension of seeking support is also positively correlated with the emotion-oriented stress coping style. The more strongly the individuals being in a difficult situation focus on their experienced emotions, the more often they seek social support.

We did not observe any statistically significant correlations between the taskoriented style and all the social support dimensions, i.e. the perceived support, the need for support and seeking support. Also, there were no significant correlations between the emotion-oriented style and the perceived support and the need for support.

In the light of the above-presented research results, we have confirmed the third hypothesis concerning correlations between the studied psychological variables, i.e. stress coping styles and social support dimensions.

\section{Conclusions and Discussion}

The problem of experiencing physical disability and coping with difficulties that result from this situation is very important not only from the point of view of a patient and their family but also doctors, psychologists and other medical staff. It has been shown by a great number of different theories, research, publications, social actions aimed at broadening and disseminating the knowledge in this respect.

The aim of the carried out research was the comparison of stress coping resources (i.e. social support and stress coping styles) in the groups of men with tetraplegia and able-bodied ones. The obtained research results allow us to state that the process of struggling with stress proceeds differently for men with tetraplegia and healthy ones. The reactions of healthy men are more complementary and adaptational.

The task-oriented stress coping style as the only one did not differentiate the sample groups statistically. A statistically significant differentiation in respect of remedial actions in a difficult situation concerned the other two styles: the emotion- and avoidance-oriented ones - they were used more often by the men with tetraplegia than by the healthy ones.

The reference books provide some reports consistent with the obtained results concerning the prevalence of the avoidance-oriented style in chronically ill persons (Walęcka, Rostowska, 2002; Parchomiuk, Byra, 2007).

The above-mentioned facts can be explained by the lowered self-esteem in the examined men, which is connected with using the less-efficient coping styles in difficult situations (Walęcka, Rostowska, 2002).

As it is shown in research, using the emotion-oriented stress coping style by men with tetraplegia and paraplegia is also connected with the low level of their well-being (Rostowska, Kossak, 2011). 
The examined men from both groups differed in using social support. The differences concerned all the social support dimensions. The men with tetraplegia sought support and showed the need for it more often than the healthy men. However, they less often perceived support as available to them. The obtained research results confirm that persons in a difficult situation whose agility is limited show the need for help, yet they do not always receive it or are ready to accept it (Simonton, Matthews-Simonton, Creighton, 2005).

Analyzing the obtained correlations between stress coping styles and social support dimensions, it appeared that using the task-oriented style in a difficult situation is not correlated in a statistically significant degree with social support. This might result from the effectiveness of this coping style, which is sufficient to reduce tension without help received from other people.

The strongest positive correlations occurred between the avoidance-oriented stress coping style and the need for support and seeking support. Thus, it may be presumed that a lack of independence, failing to use the task-oriented approach to a problem, escape from confrontation with it are connected with the tendency to seek and use help of other people. Such behaviours, in fact, increase the possibility of dealing successfully with a difficult situation.

The positive correlation between the emotion-oriented coping style and seeking social support may result from faith in overcoming hardships with other people's help.

To sum up, disabled persons take various remedial actions helping them to cope with stress; nevertheless, the chosen styles are not always effective. A chronically ill person shall definitely need psychological support to improve their functioning, and its main objective should be facilitating the person's adaptation to their life situation which has been dramatically changed by the illness.

\section{References}

Brzezińska A.I., Woźniak Z., Maj K. (2007). Persons with lowered agility on the labour market, p.52. Warsaw: Publishing House Academica SWPS.

Chojnacka-Szawłowska G. (2000) Crisis in cancer. [In:] De Walden-Gałuszko K. [Ed.]. Psychooncology. Kraków: Library of Polish Psychiatry.

Endler N.S., Parker J.D.A. (1990). Coping Inventory for Stressful Situations (CISS). Manual. Toronto: Multi-Health Systems.

Golinowska S. (2004). Social interaction of the disabled. Institution activity assessment. book no. 25, p.19-23. Warsaw: Institute of Labour and Social Studies.

Góralczyk E.: Child's illness in your life. Publishing House MEN, Warsaw, 1996, p.

Heszen-Niejodek I. (2007). Theories of psychological stress and coping. [In:] Strealu J. [Ed.]. Psychology. Textbook. T.3. Gdańsk: Publishing House GWP.

Heszen- Niejodek I. (2000). Psychological problems of the somatically ill. [In:] Strelau J. [Ed.]: Psychology. Textbook, p.513- 531. An individual in society and elements of applied psychology. Gdańsk: Publishing House GWP. 
Heszen -Niejodek I. (2000). Theories of psychological stress and coping. [In:] Strelau J. [Ed.]. Psychology. Textbook. T.3, p.465-492. Gdańsk: Publishing House GWP.

Juczyński Z. (2000). Coping with stress caused by cancer. [In:] De Walden - Gałuszko K. [Ed.]. Psycho-oncology, p. 23-45. Kraków: Publishing House, Library of Polish Psychiatry.

Kirenko J. (2002). Social support for the disabled. Ryki: Publishing House, Higher School of Pedagogics and Management.

Knoll N., Schwarzer R. (2004). ... a friend indeed. Social support, stress, illness, death. [In:] Sęk H., Cieślak R. [Ed.]. Social support, stress and health. Warsaw: Publishing House PWN, p.29-49.

Krasuska-Betiuk. (2010). M. Literature and the questions of illness, disability and suffering. [In:] Zasępa E. [Ed.]. Illness, disability, suffering and attitudes towards them - in theory and research, p.81-101. Warsaw: Publishing House, Academy of Special Education.

Kulesza M. (2000). Selected aspects of psychological care of chronically ill children. The Problems of Psychological-Pedagogical Consulting, 1 (12), p.67- 85.

Parchomiuk M., Byra S. (2004). Coping styles in the physically disabled. Disability and Rehabilitation, p. 19-27.

Rostowska T., Kossak D. (2011). Strategies for coping with stress in patients with tetraplegia and paraplegia. Acta Nauropsychologica, 9,1, p.31-48.

Sarason I.G. (1987). A Brief Measure of Social Support: Practical and Theoretical Implications. Journal of Social and Personal Relationships November, 4, p. 497-510.

Schwarzer R., Łuszczyńska A., Mazurkiewicz, M., Kowalska M. (2006). Berlin Social Support Scales (BSSS). The results of the introductory studies on the scales adaptation and their psychometric qualities. Psychological Studies, 44(3), p. 17-27.

Schulz U., Schwarzer R. (2003). Soziale Unterstützung Kranheitsbewältigung: BSSS. Diagnostica, 49, p. 73-82.

Simonton O.C. (2005). Matthews-Simonton S., Creighton J.L.: Triumph of life. You can in with cancer. Łódź: Publishing House Ravi.

Sęk H. (2001). On ambiguous functions of social support. [In:] Cierpiałowska L., Sęk H. [Ed.]. Clinical psychology and health psychology, p.13-32. Poznań: Publishing House, Humanior Foundation.

Stelter Ż. (2010). Suffering and loss of agility. [In:] Zasępa E. [Ed.]. Illness, disability, suffering and attitudes towards them - in theory and research, p.45-69. Warsaw: Publishing House: Academy of Special Education.

Steuden S., Okła W. (2007). Factors increasing the quality of life in he illness situation. [In:] Oleś P., Steuden S., Toczołowski J. [Ed.]. As I can see less. Vision impairment and the quality of life. Lublin: Publishing House, Scientific Society of KUL, p.195-209.

Strelau J., Jaworowska A., Wrześniewski K., Szczepaniak P. (2007). CISS- Coping Inventory for Stressful Situations. Warsaw: Publishing House: Psychological Tests Laboratory.

Szczepankowska B., Mikulski J. (1999). The disabled in the local community. Creating equal opportunities. Warsaw: Publishing House CBRRON.

Terelak J. (1995). Psychological stress. Bydgoszcz: Publishing House Branta.

Walęcka K., Rostowska T. (2002). Self-esteem and stress coping styles in women after Brest cancer operations. Psycho-oncology, 6(2), p.37-45.

Wrześniewski K. (1996). Stress coping styles vs. strategies. The problem with assessment. [In]. Heszen- Niejodek I., Ratajczak Z., [Ed.]. A man in a stressful situation. Theoretical and methodological problems, p. 44-65. Katowice: Publishing House UŚ. 